\title{
MODEL UNTUK PENETAPAN TARIF ZONA PARKIR (STUDI KASUS KOTA PADANG)
}

\begin{abstract}
Asrizal $^{1}$
ABSTRAK

Parking problem in Central Business District (CBD) of Padang City is the use of parking space on the roadside, especially on the Pasar Raya street that has exceeded capacities. Meanwhile, request of the parking space on the roads surrounding is still below the available capacity. To balance the demand and supply of the parking space in this area, a research is conducted to make a change of parking management through applying different tariff for different zones of parking. Tariff of parking in zone which have been identified, is calculated with equation of linear regression model which pursuant to probability of Willingness to Pay by service users. The antecedent survey which conducted to some respondent, indicate that factors such as tariff, distance, duration and accessibility, having an effect which enough to influence the probability of service user in choosing of location of parking. All factors did not correlate each other. Then, a research was conducted by collecting samples of data to 100 respondents through questioner survey and interview. The format of questioner was designed by using design of experiment "FULL FACTORIAL" which consisted of 4 attribute and 2 levels at existing condition and hypotheses. The result of survey was processed by using Spreadsheet Software with a multiple linear regression model, where $\mathrm{Y}$ is the function of utilities to Tariff (X1), Distance (X2), Duration (X3) and Accessibility (X4). The results of survey show the majority of respondent characteristic are males and the range of age is between $26-43$ years. They are commonly private employee, and their average income are about Rp. 2.000 .000 - Rp. 3.000 .000 per month. From the data analysis of stated preference, an equation model of $\mathrm{Y}=2.9123-0.0005$ (X1) - 0.0133 (X2) 0.0225 (X3) 0.0208 (X4) was obtained, value of R2 was 0.70 and has qualified the statistical test. The model was more sensitive to change of distance and duration of parking. From the application of model pursuant to Willingness to Pay by service user at the CBD area of Padang, it was obtained that the tariff of parking are Rp. 3.198 for zone 1 and Rp. 2.392 for zone 2.
\end{abstract}

Kata kunci : Tariff parking zone, Willingness to Pay, Stated Preference.

\section{PENDAHULUAN}

\subsection{Latar Belakang}

Permasalahan parkir di tepi jalan (on street parking) jauh lebih kompleks. Tidak saja ketersediaan ruang yang cukup di tepi jalan, tetapi juga gangguan yang ditimbulkan oleh aktivitas parkir itu sendiri terhadap aliran lalu lintas yang ada. Pada tempat-tempat keramaian atau di pusat-pusat aktivitas masyarakat di mana tingkat kebutuhan parkir sangat tinggi, fasilitas parkir seringkali menimbulkan permasalahan serius. Orang selalu menginginkan parkir sedekat mungkin dengan tujuan perjalanannya. Sifat lahirilah inilah yang sering menyebabkan aktivitas parkir menjadi sumber terjadinya traffic crowded.

\footnotetext{
${ }^{1}$ Staf Pengajar Sekolah Tinggi Transportasi Darat
} 
Berdasarkan hasil Studi Potensi Parkir pada beberapa ruas jalan di pusat Kota Padang tahun 2008 yang dilakukan oleh Dinas Perhubungan Kota Padang, diketahui bahwa lokasi parkir berlapis terjadi di Jalan Pasar Raya, sementara jalan disekitarnya masih dibawah kapasitas yang tersedia. Salah satu manajemen perparkiran yang dapat dilakukan adalah penerapan parking zone sebagai basis untuk menentukan lokasi tertentu dengan tarif parkir yang berbeda.

\subsection{Permasalahan}

Tidak seimbangnya penggunaan ruang parkir antar ruas jalan, karena ada perbedaan potensi demand di masing-masing ruas jalan.

\subsection{Maksud dan Tujuan Penelitian}

1. Mengetahui dan menganalisa seberapa besar faktor-faktor yang mempe-ngaruhi pemilihan lokasi parkir berdasarkan preferensi pengguna jasa.

2. Melakukan analisis WTP dan membuat persamaan model untuk penetapan tarif zona parkir di kawasan Pusat Kota Padang.

\subsection{Ruang Lingkup}

1. Lingkup wilayah study adalah Kawasan Pasar Raya Padang

2. Lingkup kajian adalah pemodelan Willingness To Pay (WTP) pengguna jasa parkir dengan teknik stated preference. 


\section{METODOLOGI PENELITIAN}

\subsection{Tahapan Penelitian dan Bagan Alir}

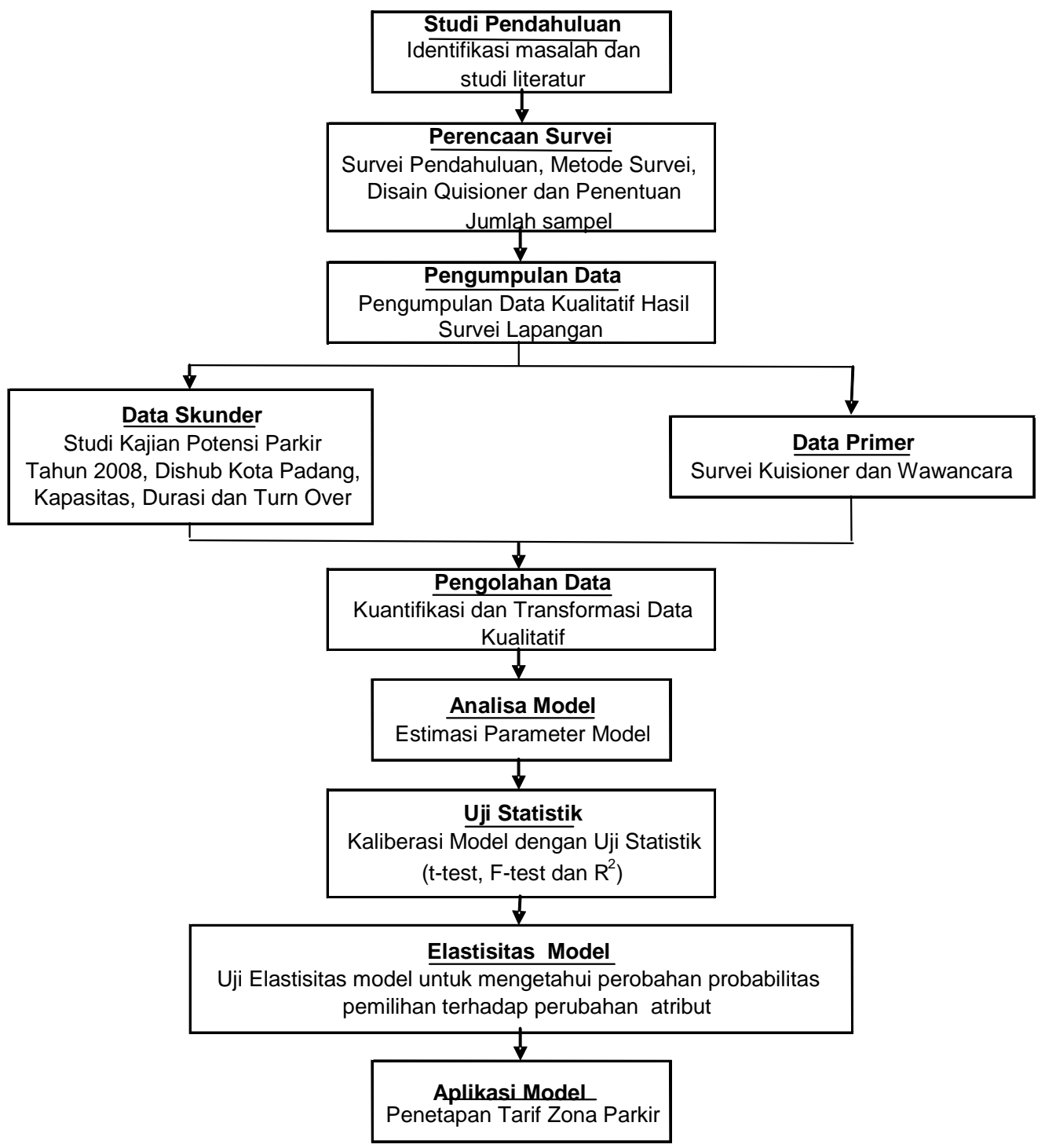

Gambar 1 Bagan Alir Metodologi Penelitian

\subsection{Studi Pendahuluan}

Hasil uji korelasi antar variabel dari model utilitas yang menggunakan persamaan regresi linear berganda, diperoleh hasil bahwa faktor tarif $(-0,425)$, jarak $(-0,473)$, durasi $(0,485)$ dan aksesibilitas $(-0,338)$ mempunyai hubungan yang cukup kuat terhadap utilitas pengguna jasa dalam memilih lokasi parkir di Jl. Pasar Raya Padang, Selanjutnya faktorfaktor tersebut ditetapkan sebagai variabel bebas dengan nilai atribut yang didefenisikan sebagai berikut : 
Tabel. 2 Nilai Atribut Level 1 dan Level 2

\begin{tabular}{|l|l|l|l|}
\hline \multirow{2}{*}{ NO } & \multirow{2}{*}{ ATRIBUT } & \multicolumn{2}{|l|}{ Defenisi } \\
\cline { 3 - 4 } & & $\begin{array}{l}\text { Level 1 } \\
\text { (existing) }\end{array}$ & $\begin{array}{l}\text { Level 2 } \\
\text { (hipotesis) }\end{array}$ \\
\hline 1. & Tarif parkir & Rp. 2.000 & Rp. 3.000 \\
\hline 2. & Jarak berjalan kaki ke lokasi tujuan & 100 meter & 200 meter \\
\hline 3. & Durasi parkir & 120 menit & 60 menit \\
\hline 4. & Aksesibilitas dengan besaran sudut parkir & $45^{0}$ & $90^{0}$ \\
\hline
\end{tabular}

Sumber : Hasil Analisis

Asumsi yang diambil dalam pengambilan nilai level atribut sebagai berikut : Tarif parkir yang berlaku pada lokasi penelitian adalah Rp.2.000, lokasi penelitian berada pada zona 1 dengan radius 100 meter, durasi parkir rata-rata dari hasil pengamatan adalah 2 jam dan manajemen perparkiran diatur dengan parkir sudut $45^{\circ}$.

Disain eksperimen yang dipergunakan dalam menyusun kuisioner adalah konsep full factorial dengan 2 level dan 4 atribut, sehingga diperoleh jumlah kuisioner dengan kombinasi atribut sebanyak $2^{4}=16$ kuisioner (options).

\subsection{Metode Survei}

Metode survei dilakukan dengan cara sampling, yaitu dengan cara melakukan wawancara dan pengisian kuisioner yang telah di disain mengunakan teknik stated preference dengan sampel sebanyak 100 responden

\subsection{Pengumpulan dan Pengolahan Data}

Data primer berasal dari hasil survei kuesioner dan wawancara sedangkan data sekunder diperoleh dari hasil Studi Kajian Potensi Parkir Kota Padang tahun 2008. Data yang terkumpul masih dalam skala semantik dan dilakukan kuantifikasi dan transformasi ke dalam skala numerik.

\subsection{Analisa Model, Uji Statistik dan Elastisitas Model}

Analisa dilakukan dengan cara analisa regresi linear berganda, analisa statistik melalui pemakaian konsep significance test (t-test dan F-test) dan ukuran kesesuaian model (R-squre). Elastisitas model dilakukan dengan maksud untuk mengetahui sensitifitas model terhadap perubahan nilai probabilitas pemilihan lokasi parkir.

\section{HASIL DAN PEMBAHASAN}

\subsection{Model Untuk Penetapan Tarif Zona Parkir}

\subsubsection{Analisa Regresi Data Stated Preference}

Dengan menggunakan pilihan rating, responden memberikan pilihan terhadap point rating yang disajikan dalam bentuk skala semantik, kemudian ditransformasikan ke dalam skala numerik dengan menggunakan skala logit biner, pada probabilitas tertentu untuk masing-masing point rating seperti ditunjukkan pada Tabel.3. 
Tabel 3. Nilai Skala Numerik

\begin{tabular}{|l|l|l|}
\hline \multirow{2}{*}{ Point Rating } & Nilai Transformasi \\
\cline { 2 - 3 } & Skala Probabilitas & Skala Numerik \\
\hline 1(pasti) & 0.90 & 2,1972246 \\
\hline 2(mungkin ya) & 0,70 & 0,8472979 \\
\hline 3(ragu-ragu) & 0,50 & 0 \\
\hline 4(mungkin tidak) & 0,30 & $-0,8472979$ \\
\hline 5(tidak) & 0,10 & $-2,1972246$ \\
\hline
\end{tabular}

Sumber : Hasil Analisis

3.1.2 Persamaan Model Utilitas

$$
Y=a+b_{1} X_{1}+b_{2} X_{2}+b_{3} X_{3}+b_{4} X_{4}
$$

Dimana :

$\mathrm{Y}=$ Utilitas

$\mathrm{X}_{1}=$ Tarif Parkir, Rp. 2.000 dan Rp.3000

$\mathrm{X}_{2}=$ Jarak berjalan kaki ke lokasi tujan, 100 meter dan 200 meter

$\mathrm{X}_{3}=$ Durasi Parkir, 120 menit dan 60 menit

$\mathrm{X}_{4}=$ Aksesibilitas dengan besaran sudut parkir, $45^{\circ}$ dan $90^{\circ}$

\subsubsection{Kompilasi Data}

1. Persamaan Model Utilitas 100 Responden

$$
\begin{aligned}
& \mathrm{Y}=2,9123-0,0005 \mathrm{X}_{1}-0,0133 \mathrm{X}_{2}+0,0255 \mathrm{X}_{3}-0,0208 \mathrm{X}_{4} \\
& \mathrm{t}=(22,6151) \quad \mathrm{t} 1=(-16,2931) \quad \mathrm{t} 2=(-37,8099) \quad \mathrm{t} 3=(38,2839) \quad \mathrm{t} 4=(-26,5832) \\
& \mathrm{R}^{2}=0,70 \quad \mathrm{~F}=966,847 \quad \text { Jumlah Observasi }=1600
\end{aligned}
$$

\begin{tabular}{|c|c|c|c|c|c|}
\hline \multirow[t]{2}{*}{ No } & \multirow[t]{2}{*}{ Persamaan Model } & \multicolumn{2}{|c|}{ Jumlah } & \multirow[t]{2}{*}{$\mathbf{R}^{2}$} & \multirow[t]{2}{*}{$\mathbf{F}$} \\
\hline & & Sampel & Observasi & & \\
\hline 1. & 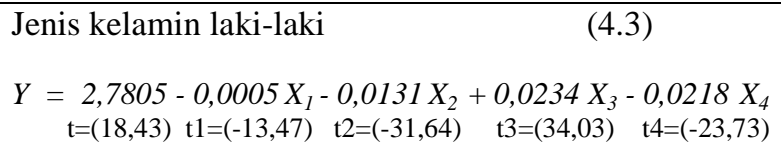 & 73 & 1168 & 0,71 & 726,15 \\
\hline 2 . & Jenis kelamin perempuan & 27 & 432 & 0,70 & 252,42 \\
\hline 3. & $Y=\begin{array}{ccc}3,2687-0,0006 X_{1}-0,0141 X_{2}+0,0200 X_{3}-0,0183 X_{4} \\
\mathrm{t}=(13,43) & \mathrm{t} 1=(-9,36) & \mathrm{t} 2=(-21,09) \quad \mathrm{t} 3=(18,02) \quad \mathrm{t} 4=(-12,33)\end{array}$ & & & & \\
\hline 4. & $\begin{array}{l}\text { Usia } 17-25 \text { tahun } \\
\begin{array}{ll}Y=3,2687-0,0006 X_{1}-0,0141 X_{2}+0,0200 X_{3}-0,0183 X_{4} \\
\mathrm{t}=(6,98) \quad \mathrm{t} 1=(-5,31) \quad \mathrm{t} 2=(-9,37) \quad \mathrm{t} 3=(7,76) \quad \mathrm{t} 4=(-6,75)\end{array}\end{array}$ & 7 & 112 & 0,67 & 55,49 \\
\hline 5. & Usia 26 - 34 tahun & 23 & 368 & 0,69 & 208,23 \\
\hline 6. & $\begin{array}{l}Y=2,5046-0,0005 X_{1}-0,0124 X_{2}+0,0238 X_{3}-0,0200 X_{4} \\
\mathrm{t}=(9,13) \quad \mathrm{t} 1=(-7,39) \quad \mathrm{t} 2=(-16,53) \quad \mathrm{t} 3=(19,02) \quad \mathrm{t} 4=(-11,94) \\
\text { Usia } 35-43 \text { tahun }\end{array}$ & 47 & 752 & 0,72 & 488,16 \\
\hline 7. & $Y=\begin{array}{c}2,9848-0,0005 X_{1}-0,0135 X_{2}+0,0231 X_{3}-0,0216 X_{4} \\
\mathrm{t}=(16,11) \quad \mathrm{t} 1=(-11,55) \quad \mathrm{t} 2=(-26,57) \quad \mathrm{t} 3=(27,34) \quad \mathrm{t} 4=(-19,12)\end{array}$ & 23 & 368 & 0,71 & 223,88 \\
\hline
\end{tabular}

2. Persamaan Model Karakteristik Pengguna Jasa.

Tabel 4. Persamaan Model Karakteristik Pengguna Jasa 


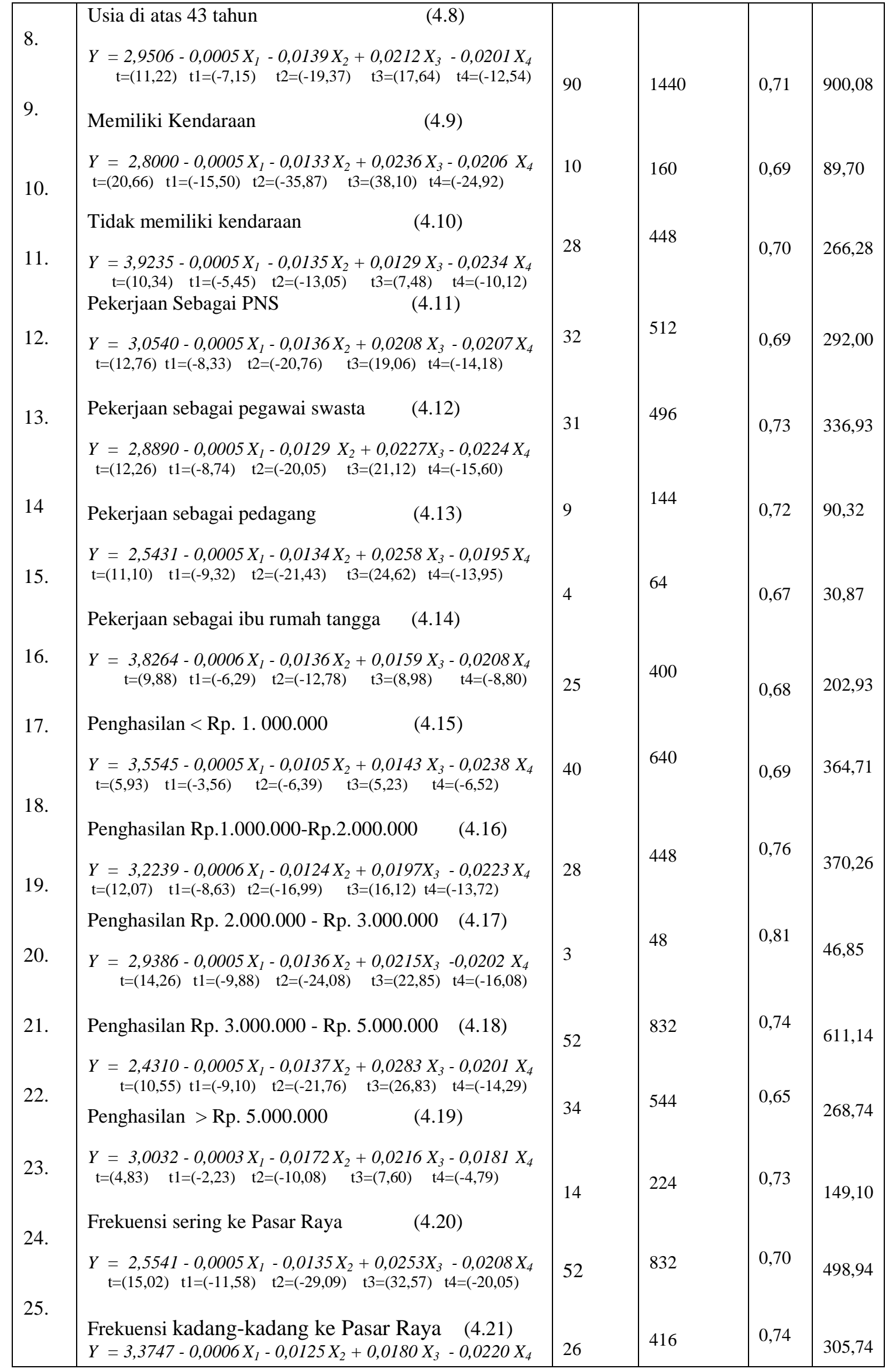




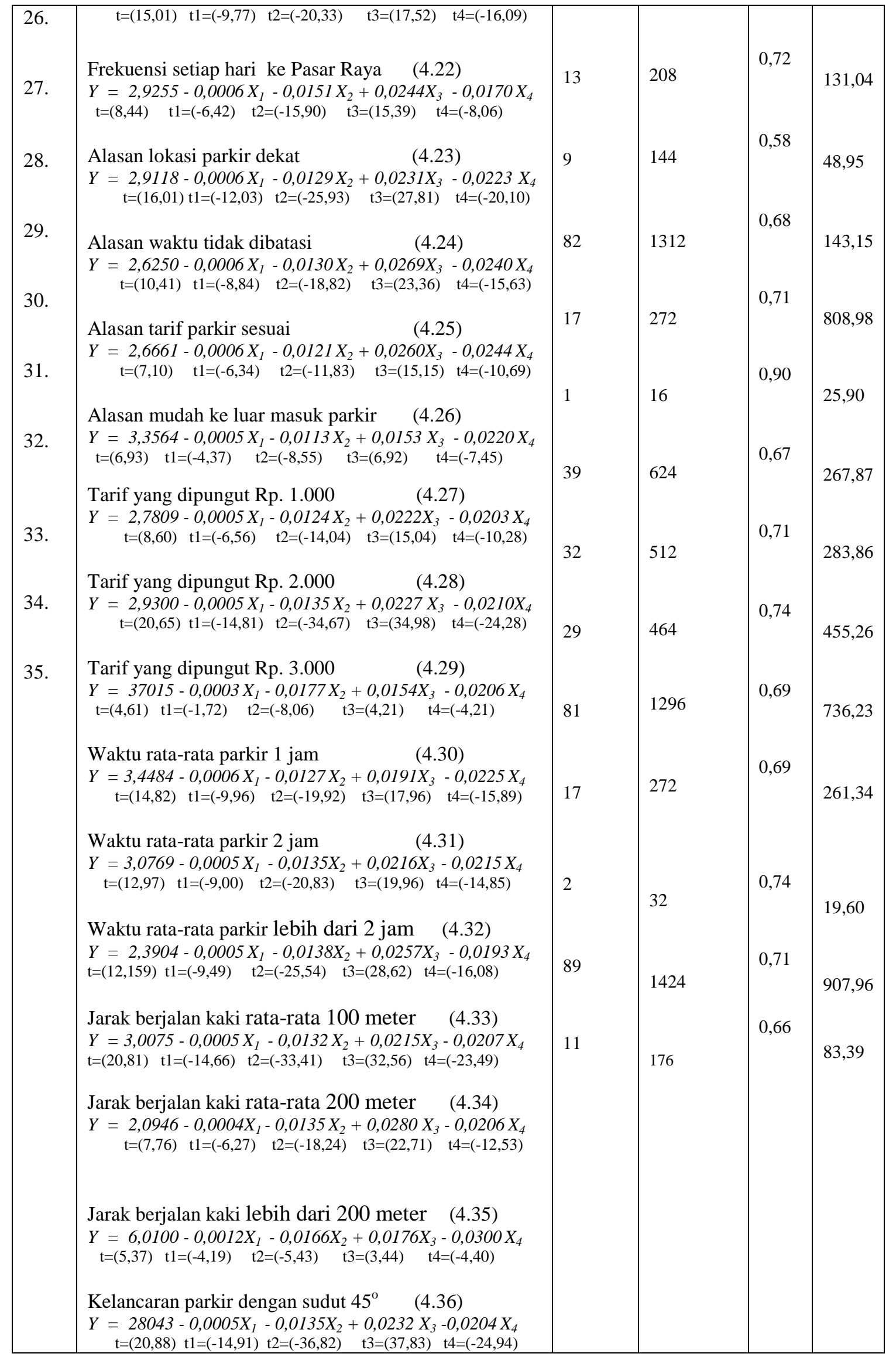




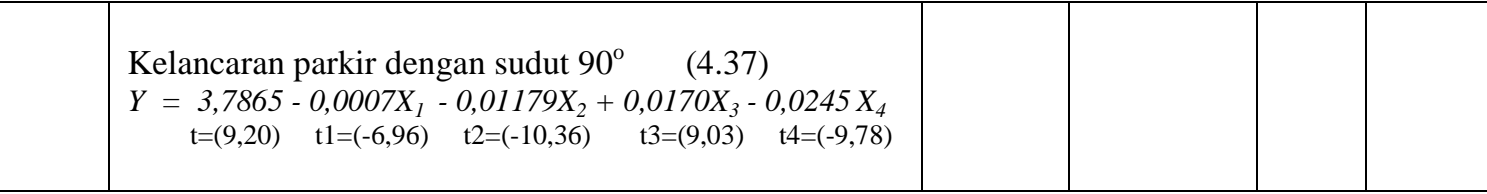

Sumber : Hasil Analisis

\subsection{Analisa Model}

\subsubsection{Pengujian koefisien regresi secara parsial (t-test)}

Dengan menggunakan table distribusi t, Nilai level of significance $(\alpha)=0,05$. Jumlah observasi $>$ 120. diperoleh nilai t-kritis $=1,960$. Hasil pengujian t-test untuk keempat vaiabel menunjukkan bahwa sebagian besar nilai t-stat > t-kritis, dan hanya terdapat 1 persamaan model yang tidak lolos uji t-test yaitu : Persamaan 4.29, model untuk tarif yang diminta juru parkir sebesar Rp. 3.000.

\subsubsection{Pengujian Pengaruh Atribut Secara Bersama (F-test)}

Dengan menggunakan table distribusi F, maka : Nilai level of significance $(\alpha)=0,05$, Jumlah observasi $>120$,Diperoleh nilai F-kritis $=2,37$. Hasil pengujian F-test menunjukkan bahwa secara umum nilai F-stat model lebih besar dari F-kritisnya.

\subsubsection{Pengukuran Persentase Pengaruh Semua Atribut $\left(\mathrm{R}^{2}\right)$}

Nilai koefisien determinasi $\left(R^{2}\right)$ dari 36 persamaan model utilitas hasil regresi diperoleh nilai $\left(R^{2}\right)$ terkecil 0,58 dan terbesar 0,90. Dari 36 model utilitas hasil pengukuran persentase pengaruh semua atribut $\left(\mathrm{R}^{2}\right)$ dan pertimbangan jumlah sampel, terdapat 29 persamaan model yang terpilih dan 7 persamaan model utilitas yang tidak dapat dipilih karena jumlah sampel yang ada tidak dapat menggambarkan keadaan yang sebenarnya.

\subsection{Probabilitas Willingness To Pay}

Berdasarkan persamaan model hasil regresi pada persamaan model 4.2 , diperoleh nilai probabilitas Willingness To Pay dari masing-masing pilihan (options) seperti pada Tabel. 5 berikut :

Tabel. 5 Probabilitas WTP Masing-Masing Pilihan (Options)

\begin{tabular}{|l|l|l|l|l|l|l|}
\hline OPTIONS & Tarif & Jarak & Durasi & Aksesbilitas & Utilitas & Probabilitas (wtp) \\
\hline 1 & 2000 & 200 & 60 & 90 & -1.27 & -0.28 \\
\hline 2 & 3000 & 200 & 60 & 45 & -0.83 & -0.18 \\
\hline 3 & 3000 & 200 & 120 & 90 & -0.42 & -0.09 \\
\hline 4 & 3000 & 100 & 60 & 90 & -0.44 & -0.10 \\
\hline 5 & 3000 & 200 & 60 & 90 & -1.77 & -0.38 \\
\hline 6 & 2000 & 100 & 60 & 90 & 0.06 & 0.01 \\
\hline 7 & 3000 & 200 & 120 & 45 & 0.52 & 0.11 \\
\hline 8 & 2000 & 200 & 120 & 90 & 0.08 & 0.02 \\
\hline 9 & 3000 & 100 & 60 & 45 & 0.50 & 0.11 \\
\hline 10 & 2000 & 200 & 60 & 45 & -0.33 & -0.07 \\
\hline 11 & 3000 & 100 & 120 & 90 & 0.91 & 0.20 \\
\hline 12 & 2000 & 100 & 120 & 45 & 2.35 & 0.51 \\
\hline 13 & 2000 & 100 & 120 & 90 & 1.41 & 0.31 \\
\hline 14 & 3000 & 100 & 120 & 45 & 1.85 & 0.40 \\
\hline 15 & 2000 & 100 & 60 & 45 & 1.00 & 0.22 \\
\hline 16 & 2000 & 200 & 120 & 45 & 1.02 & 0.22 \\
\hline
\end{tabular}

Sumber : Hasil Analisis 


\subsection{Elastisitas Persamaan Model}

Elastisitas pada penelitian ini digunakan elastisitas busur. Nilai atribut yang dipergunakan adalah options nomor 12 yang memiliki probabilitas yang terbesar.. Elastisitas pemilihan lokasi parkir berdasarkan persamaan 4.2 terhadap masing-masing atribut adalah seperti Tabel. 6 berikut :

Tabel. 6 Elastisitas probabilitas pemilihan parkir

\begin{tabular}{|l|l|l|l|l|}
\hline \multirow{2}{*}{ Parameter } & \multicolumn{4}{c|}{ ATRIBUT } \\
\cline { 2 - 5 } & \multicolumn{1}{|c|}{ TARIF } & \multicolumn{1}{c|}{ JARAK } & \multicolumn{1}{c|}{ DURASI } & \multicolumn{1}{c|}{ AKSESIBILITAS } \\
\hline$\Delta \mathrm{x}$ & -1000 & -100 & 60 & -45 \\
\hline$\Delta \mathrm{Y}$ & $-0,11$ & $-0,29$ & $-0,29$ & $-0,20$ \\
\hline Elastisitas langsung & 0,43 & 0,57 & $-0,57$ & 0,39 \\
\hline
\end{tabular}

Sumber : Hasil Analisis

Probabilitas pengguna jasa akan parkir sangat sensitif terhadap perubahan jarak berjalan kaki ke lokasi tujuan dan perubahan durasi parkir yang diikuti dengan perubahan tarif parkir, sedangkan atribut yang kurang sensitif terhadap model utilitas adalah perubahan aksesibilitas dengan besaran sudut parkir.

\subsection{Aplikasi Model}

Aplikasi model untuk penetapan tarif parkir pada masing-masing zona dilakukan melalui penggunaan persamaan 4.2. Berdasarkan kelebihan permintaan pada lokasi parkir.

\subsubsection{Tarif Parkir Zona 1}

Kapasitas parkir (SRP) yang tersedia pada zona 1 kondisi existing adalah 1098 SRP yang terbagi pada 7 lokasi parkir atau rata-rata kapasitas (SRP) pada masing-masing lokasi di zona ini adalah 157 SRP per lokasi. Sedangkan jumlah parkir harian rata-rata pada zona 1 adalah sebesar 216, sehingga pada zona 1 terjadi kelebihan permintaan parkir sebesar $38 \%$. Untuk mengendalikan permintaan parkir berdasarkan karakteristik pengguna jasa agar sesuai dengan kapasitas SRP yang tersedia pada zona 1, maka nilai probabilitas WTP pengguna jasa di zona ini yang semula adalah $100 \%$ dikurangi dengan persentase kelebihan permintaan, sehingga menjadi $62 \%$ atau 0,62. Dengan probabilitas WTP sebesar 0,62 (Utilitas = 0,490) dan X2 (jarak) 100 meter, X3 (durasi) 78 menit X4 (aksesibilitas) dengan sudut parkir $60^{\circ}$, diperoleh besarnya tarif parkir pada zona 1 adalah Rp. 3.198.

\subsubsection{Tarif Parkir Zona 2}

Kapasitas parkir (SRP) yang tersedia pada zona 2 kondisi existing adalah 1502 SRP yang terbagi pada 6 lokasi parkir atau rata-rata kapasitas (SRP) pada masing-masing lokasi di zona ini adalah 250 SRP per lokasi. Sedangkan jumlah parkir harian rata-rata pada zona 2 adalah sebesar 194, sehingga pada zona ini hanya tersedia ruang parkir sebesar $22 \%$ untuk menampung permintaan parkir sebesar $62 \%$. Pada zona ini akan terjadi kelebihan permintaan sebesar $40 \%$ sebagai akibat perubahan tarif parkir pada zona 1 . Untuk mengendalikan permintaan parkir agar sesuai dengan kapasitas SRP yang tersedia pada zona ini, maka nilai probabilitas WTP pengguna jasa di zona ini yang semula adalah $100 \%$ dikurangi dengan persentase kelebihan perintaan, sehingga menjadi $60 \%$ atau 0,60. Dengan probabilitas WTP sebesar 0,60 (Utilitas $=0,322)$ dan X2 (jarak) 150 meter, X3 (durasi) 72 menit X4 (aksesibilitas) dengan sudut parkir ${ }^{450}$, diperoleh besarnya tarif parkir pada zona 2 adalah Rp. 2.392. 


\section{KESIMPULAN DAN SARAN}

\subsection{Kesimpulan}

1. Persamaan model terpilih untuk penetapan tarif zona parkir dan memenuhi syarat uji statistik yaitu :

$$
\begin{aligned}
& \mathrm{Y}=2,9123-0,0005 \mathrm{X}_{1}-0,0133 \mathrm{X}_{2}+0,0225 \mathrm{X}_{3}-0,0208 \mathrm{X}_{4} \\
& \mathrm{t}=(22,61) \mathrm{t} 1=(-16,29) \quad \mathrm{t} 2=(-37,80) \quad \mathrm{t} 3=(38,28) \quad \mathrm{t} 4=(-26,58)
\end{aligned}
$$

Dengan $\mathrm{R}^{2}=0,708$ dan $\mathrm{F}=966,847$, dimana $\mathrm{Y}$ adalah utilitas, $\mathrm{X}_{1}$ (Tarif parkir ), $\mathrm{X}_{2}$ (Jarak berjalan kaki), $\mathrm{X}_{3}$ (Durasi Parkir) dan $\mathrm{X}_{4}$ (Aksesibilitas dengan besaran sudut parkir).

2. Probabilitas pengguna jasa akan parkir sangat sensitif terhadap perubahan jarak berjalan kaki dan perubahan durasi yang diikuti dengan perubahan tarif parkir yang dipungut, sedangkan atribut yang kurang sensitif terhadap perubahan aksesibilitas dengan besaran sudut parkir.

3. Dari aplikasi persamaan model, diperoleh besarnya tarif zona parkir berdasarkan Willingness To Pay pengguna jasa pada Central Business Distrik (CBD) Kota Padang yaitu sebesar Rp. 3.198 untuk zona 1 (satu), Rp. 2.392 untuk zona 2 (dua).

\subsection{Saran}

1. Perlu dilakukan penelitian lebih lanjut dengan menambah atribut lainnya sehingga diperoleh korelasi yang cukup signifikan terhadap Willingness To Pay pengguna jasa dalam memilih lokasi parkir di kawasan business Kota Padang.

2. Untuk penetapan nilai atribut dalam aplikasi model, maka perlu penelitian secara seksama terhadap nilai atribut, agar nilai atribut yang dipergunakan nantinya sesuai dengan karakteristik pengguna jasa parkir.

3. Surveyor disarankan lebih berkomunikatif dalam melakukan survei wawancara, sehingga responden mendapat gambaran yang jelas dalam menentukan pilihannya.

\section{DAFTAR KEPUSTAKAAN}

Daldjoeni, N (1977) Geogeafi Baru ; Organisasi Keruangan Dalam Teori dan Praktek, Bandung ; Alumni. Dishub Kota Padang (2008), Kajian Potensi Parkir Kawasan Pasar Raya, Pemerintah Kota Padang 2008.

Ike Sri Novita (2009), Model Utilitas Pemilihan Moda Antara Kendaran Pribadi dan Travel Dengan Teknik Stated Preference Rute Padang - B.Tinggi, Skripsi Mahasiswa Jurusan Teknik Sipil Unand Padang.

Kennedy, Jhon B (1976) Basic Statistical Methods For Engineers and Scientists, 2nd Edition, Harper International Edition, Thomas Y. Crowel Company, Harper \& Row, Publishers, New York Harger Sluwn San Francisco London

Kurniati, Titi (2000) Analisis kebutuhan angkutan Taksi Kota Bandung Dengan Teknik Stated Preference, Bahan Seminar 3 Bidang Studi Rekayasa Transportasi Program Magister Teknik Sipil Fakultas Pascasarjana ITB.

Pearmain. D, Swanson.. J, (1991) Stated Preference Techniques, A Guide to Practice, second edition,

Tamin, O.Z. (1997) Perencanaan dan Pemodelan Transportasi. ITB: 1997.

Tamin, Ofyar Z. et. al. (1999) Evaluasi Tarif Angkutan Umum dan Analisis 'Ability to Pay' (ATP) dan 'Willingness to Pay' (WTP) di DKI Jakarta. Jurnal Transportasi Jurusan Teknik Sipil ITB Vol.1 No.2. Desember 1999.

Riwidikdo, Handoko (2008) Statika Terapan Dengan Program R, versi 2.5.1 (Open Source), Bidang Kesehatan dan Umum, Yogyakarta, Mitra Cendikia Press.

Walpole, R.E. dan Myers, R.H.Terjemahan Sembiring, R.K. (1986), Ilmu Peluang dan Statistika Untuk Insinyur dan Ilmuwan. Penerbit ITB.Bandung:1986. 